\title{
Persistent Bidirectional Optical Switching in the 2D High-Spin Polymer $\left\{\left[\mathrm{Fe}(\mathrm{bbtr})_{3}\right]\left(\mathrm{BF}_{4}\right)_{2}\right\}_{\infty}$
}

\author{
Pradip Chakraborty, ${ }^{\dagger}$ Robert Bronisz, ${ }^{\#}$ Céline Besnard, ${ }^{\ddagger}$ Laure Guénée, ${ }^{\ddagger}$ Phil Pattison, ${ }^{\S} \|$ \\ and Andreas Hauser* ${ }^{*} \dagger$
}

${ }^{\dagger}$ Département de Chimie Physique, Université de Genève, 30 Quai Ernest-Ansermet, CH-1211 Genève 4, Switzerland

${ }^{\#}$ Faculty of Chemistry, University of Wrocław, F. Joliot-Curie 14, Pl-50-383 Wrocław, Poland

${ }^{\ddagger}$ Laboratoire de Cristallographie, Université de Genève, 24 Quai Ernest-Ansermet, CH-1211 Genève 4, Switzerland

${ }^{\S}$ Laboratory of Crystallography, EPFL, CH-1015 Lausanne, Switzerland

"SNBL (ESRF), Grenoble, France

Supporting Information

ABSTRACT: In the covalently linked 2D coordination network $\left\{\left[\mathrm{Fe}(\mathrm{bbtr})_{3}\right]\left(\mathrm{BF}_{4}\right)_{2}\right\}_{\infty}$, bbtr $=1$,4-di $(1,2,3$-triazol1 -yl)butane, the iron(II) centers stay in the high-spin (HS) state down to $10 \mathrm{~K}$. They can, however, be quantitatively converted to the low-spin (LS) state by irradiating into the near-IR spin allowed ${ }^{5} \mathrm{dd}$ band and back again by irradiating into the visible ${ }^{1} \mathrm{dd}$ band. The compound shows true light-induced bistability below $100 \mathrm{~K}$, thus, having the potential for persistent bidirectional optical switching at elevated temperatures.

B idirectional switching between two states of a system is of importance for applications in a large number of fields, ${ }^{1}$ and spin-crossover compounds of transition metal ions, in particular those of iron(II), have been considered prototypes for such switchable materials for more than a decade. ${ }^{2}$ This is because they can be switched between the two lowest-energy spin states, namely, the low-spin (LS) and the high-spin (HS) state, thermally, ${ }^{3}$ by applying pressure, ${ }^{4}$ in pulsed magnetic fields, ${ }^{5}$ chemically, ${ }^{6}$ as well as optically. ${ }^{7}$ The latter has been achieved for the LS $\rightarrow$ HS conversion in the so-called LIESST effect (light-induced excited spin state trapping) at low temperatures for a large number of iron(II) spin-crossover systems. ${ }^{7,8}$ Invariably, the light-induced HS state is, however, a metastable state, albeit in some cases with a very long lifetime below $\sim 50 \mathrm{~K}^{7,8}$ For iron(II) complexes with no low-energy metal-ligand charge transfer (MLCT) transitions, lightinduced HS $\rightarrow$ LS conversion (reverse-LIESST) is likewise possible through irradiation in the near-IR, ${ }^{9}$ and Bousseksou et al. have demonstrated bidirectional switching by pulsed laser irradiation within the thermal hysteresis of a strongly cooperative iron(II) spin-crossover system near room temperature. $^{10}$

Partial bidirectional switching was demonstrated in tetrazole based systems some 15 years ago, with memory effects up to $\sim 70 \mathrm{~K}^{11}$ In the present communication, we describe the photophysical properties of the $2 \mathrm{D}$ network $\left\{\left[\mathrm{Fe}(\mathrm{bbtr})_{3}\right]\right.$ $\left.\left(\mathrm{BF}_{4}\right)_{2}\right\}_{\infty}$, bbtr $=1,4-\operatorname{di}(1,2,3$-triazol-1-yl)butane, in which, in contrast to the $\mathrm{ClO}_{4}^{-}$derivative, ${ }^{12}$ the iron(II) centers remain in the HS state down to $10 \mathrm{~K},{ }^{13}$ but can quantitatively and reversibly be switched back and forth between the two states using energy-selective excitation in the near-IR and the visible, respectively. Strong cooperative effects result in a persistent light-induced bistability below $100 \mathrm{~K}$.

Figure 1 shows single crystal absorption spectra of a small crystal $\left(\sim 300 \times 300 \times 75 \mu \mathrm{m}^{3}\right)$ with the light propagating

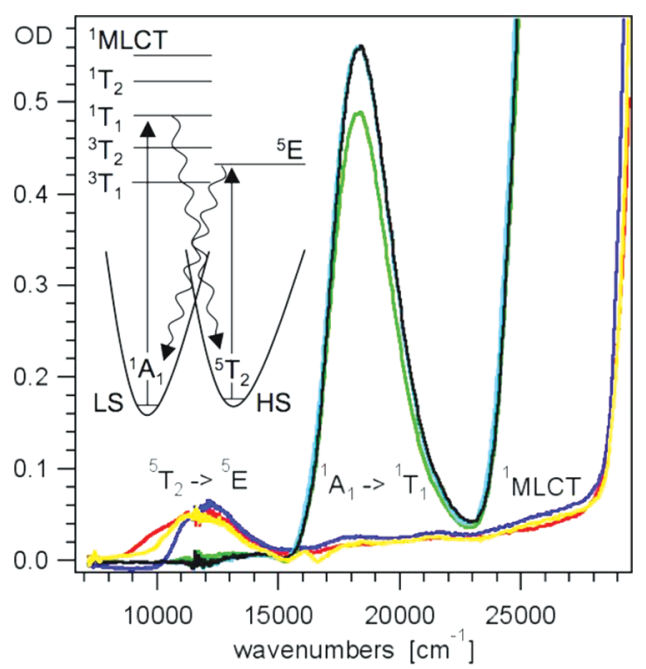

Figure 1. Single crystal absorption spectra of $\left\{\left[\mathrm{Fe}(\mathrm{bbtr})_{3}\right]\left(\mathrm{BF}_{4}\right)_{2}\right\}_{\infty}$ at $295 \mathrm{~K}$ (red), $10 \mathrm{~K}$ on slow cooling (blue), at $10 \mathrm{~K}$ after irradiation at $12050 \mathrm{~cm}^{-1}$ (green), and on subsequent warming to $60 \mathrm{~K}$ (light blue), recooling to $10 \mathrm{~K}$ (black), and finally on warming to $120 \mathrm{~K}$ (yellow). Inset: schematic of the relevant electronic states and processes.

along the $c$-axis at room temperature (red) and $10 \mathrm{~K}$ (blue) with a cooling rate of $0.2 \mathrm{~K} / \mathrm{min}$. Both are empty in the visible and show just the characteristic ${ }^{5} \mathrm{~T}_{2} \rightarrow{ }^{5} \mathrm{E}$ ligand-field transition of the HS species at $12050 \mathrm{~cm}^{-1}$, as proof that the iron(II) centers remain in the $\mathrm{HS}$ state down to $10 \mathrm{~K}$. Prolonged irradiation at $12050 \mathrm{~cm}^{-1}(830 \mathrm{~nm})$ results in almost total bleaching of this band and replacement by a more intense band at $18200 \mathrm{~cm}^{-1}$ readily attributed to the spin-allowed ligand-

Received: December 21, 2011

Published: February 21, 2012 
field ${ }^{1} \mathrm{~A}_{1} \rightarrow{ }^{1} \mathrm{~T}_{1}$ transition of the LS species, as well as steep rise above $25000 \mathrm{~cm}^{-1}$ toward an intense ${ }^{1}$ MLCT transition. Although it is obvious that the majority of the complexes have been transformed to the LS state, this spectrum does not yet allow for a quantitative determination of the fraction of photoconverted complexes.

Surprisingly, upon heating the crystal from $10 \mathrm{~K}$ at a rate of $0.2 \mathrm{~K} / \mathrm{min}$, the intensity of the ${ }^{1} \mathrm{~A}_{1} \rightarrow{ }^{1} \mathrm{~T}_{1}$ absorption band starts to increase at $\sim 30 \mathrm{~K}$ and reaches a maximum at $60 \mathrm{~K}$, with now complete bleaching of the ${ }^{5} \mathrm{~T}_{2} \rightarrow{ }^{5} \mathrm{E}$ band. This means that rather than the LS complexes returning to the HS state, the small remaining fraction of HS complexes follow suit and convert spontaneously to the LS state, thus, resulting in a $100 \%$ LS population. With this, the light-induced LS fraction after irradiation at $12050 \mathrm{~cm}^{-1}$ and $10 \mathrm{~K}$ can be estimated at $85 \%$ from the spectra in Figure 1. This value is in line with the steady LS fraction also found for the light-induced return to the LS state in related iron(II) spin-crossover systems upon irradiation at the same energy. ${ }^{9}$ It furthermore allows to plot the evolution of the HS fraction on ramping the temperature from $10 \mathrm{~K}$ shown in Figure 2.

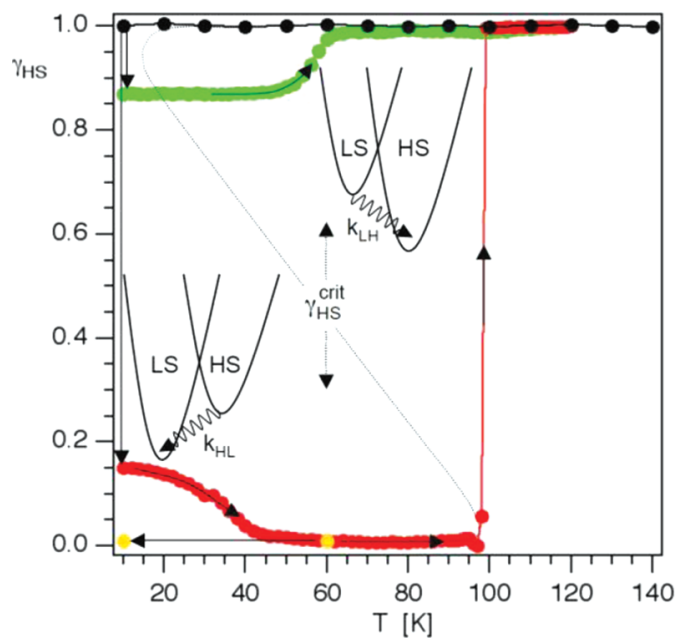

Figure 2. The high-spin fraction $\gamma_{\mathrm{HS}}$ as function of temperature: on cooling from room temperature down to $10 \mathrm{~K}$ at a rate of $0.2 \mathrm{~K} / \mathrm{min}$ (black), after irradiation at $12050 \mathrm{~cm}^{-1}$ at $10 \mathrm{~K}$ to the steady state high-spin fraction of $15 \%$ and subsequent warming to $120 \mathrm{~K}$ at a rate of $0.2 \mathrm{~K} / \mathrm{min}$ (red) or stopping at $60 \mathrm{~K}$ and recooling to $10 \mathrm{~K}$ (yellow), after a short irradiation time at $12050 \mathrm{~cm}^{-1}$ and $10 \mathrm{~K}$ resulting in an initial high-spin fraction of $85 \%$ and subsequent warming to $120 \mathrm{~K}$ at a rate of $0.2 \mathrm{~K} / \mathrm{min}$ (green).

The $100 \%$ LS population is maintained upon renewed cooling to $10 \mathrm{~K}$ and is stable indefinitely up to $100 \mathrm{~K}$. At that temperature, there is an abrupt and quantitative return to the HS state upon heating. The abruptness of this return is indicative of strong cooperative effects, and the key question to ask is whether there is a threshold value for the light-induced LS population in order for the remaining HS complexes to follow suit without further irradiation. That this must be the case is borne out by the evolution of the HS fraction upon ramping the temperature at $0.2 \mathrm{~K} / \mathrm{min}$ following only a partial light-induced LS population of $15 \%$ at $10 \mathrm{~K}$. With such a small initial LS fraction, the system indeed returns to the HS state at $\sim 60 \mathrm{~K}$, as shown in Figure 2. This occurs, therefore, at a temperature at which thermal LS $\Leftrightarrow$ HS relaxation processes set in. This is further demonstrated by the curves showing the evolution of the LS fraction, $\gamma_{\mathrm{LS}}$, at $65 \mathrm{~K}$ first as a function of time for irradiation at $12050 \mathrm{~cm}^{-1}$ for different total irradiation times in order to create different initial light-induced LS fractions, and then during the thermal relaxation at that temperature after switching off the irradiation. Clearly, there is a threshold or critical value of around $35 \%$ for the light-induced LS fraction, above which the relaxation proceeds toward full LS population and below which the system returns to full HS population after switching off the light. The sigmoidal character of the relaxation curves near the threshold value corroborates the importance of cooperative effects of elastic origin ${ }^{14}$ in this system. Globally, these act in such a way as to stabilize the majority of species. ${ }^{15}$ That is, as the system is cooled down from room temperature, the HS state is the thermodynamic ground state down to $10 \mathrm{~K}$, and the system has no need to cross over to the LS state. Upon irradiation, the light-induced LS population exerts an increasing internal pressure on the remaining HS complexes, destabilizing them to such an extent that above the critical LS population, the LS state itself becomes the ground state of the system. This implies that the title compound is a spin-crossover system having a very wide thermal hysteresis with $T_{c}^{\uparrow}=100 \mathrm{~K}$ and $T_{c}{ }^{\downarrow}$ near or formally even below $0 \mathrm{~K}$, such that the lower branch either cannot be reached thermodynamically or the relaxation is very slow and thermal equilibrium is not reached within a reasonable time.

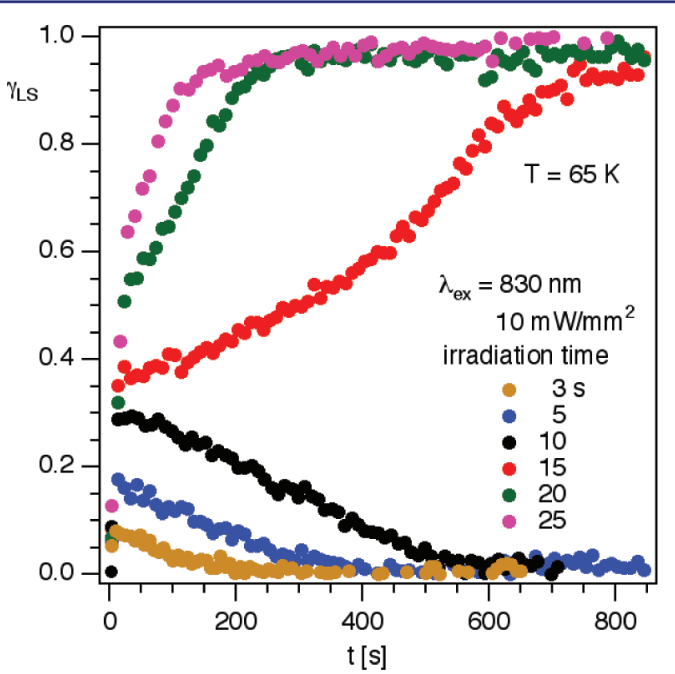

Figure 3. Evolution of the LS fraction, $\gamma_{\mathrm{LS}}$, upon irradiation at 12050 $\mathrm{cm}^{-1}, 10 \mathrm{~mW} / \mathrm{mm}^{2}$ at $65 \mathrm{~K}$ to different initial light-induced populations of the LS state by varying the irradiation time followed by the thermal relaxation at that temperature.

The light-induced HS $\rightarrow$ LS conversion can be verified by Xray crystallography. At $120 \mathrm{~K}$, the title compound crystallizes in the space group $P \overline{3}$ with one crystallographic iron(II) site and the typical $\mathrm{Fe}-\mathrm{N}$ bond length of the HS state of 2.19(1) $\AA^{12}$ At $\sim 70 \mathrm{~K}$, the crystal still is in the same space group with the same $\mathrm{Fe}-\mathrm{N}$ bond length (see Table S1, Supporting Information). Upon irradiation for $15 \mathrm{~min}$ at $12050 \mathrm{~cm}^{-1}$, the space group has changed to $P \overline{1}$ with a doubling of the $c$-axis and the iron(II) centers occupying nonequivalent lattice sites, very similar to the phase transition in the spin-crossover system of the perchlorate derivative (see Figures S1-S3, Supporting Information). The average $\mathrm{Fe}-\mathrm{N}$ bond length after irradiation at $\sim 70 \mathrm{~K}$ is $1.99(2) \AA$, indicating that at that temperature the 
light-induced transformation to the LS state followed by relaxation above the critical LS fraction is indeed quantitative.

Once in the LS state at $10 \mathrm{~K}$, another way to reestablish the HS state quantitatively is by irradiating the crystal at 21186 $\mathrm{cm}^{-1}(472 \mathrm{~nm})$, that is, into the high-energy tail of the ${ }^{1} \mathrm{~A}_{1} \rightarrow$ ${ }^{1} \mathrm{~T}_{1}$ transition, where absorption is weak in order to avoid creating large concentration gradients during the light-induced transformation. The spectrum obtained after irradiation of the sample in the LS state at this energy and at $10 \mathrm{~K}$, not explicitly shown in Figure 1, is identical to the initial $10 \mathrm{~K}$ spectrum. This is also the case at higher temperatures, for instance at $65 \mathrm{~K}$. Figure 4 demonstrates the full reversibility of the light-induced

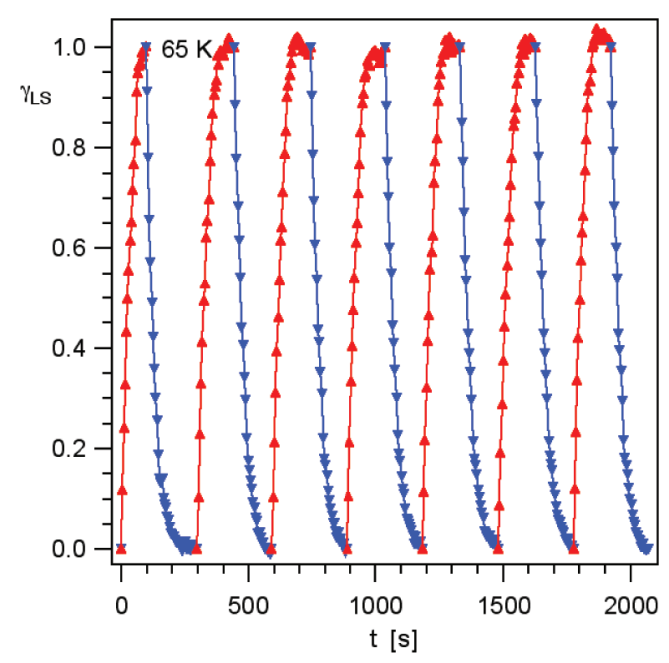

Figure 4. Evolution of the LS fraction, $\gamma_{\mathrm{LS}}$ upon irradiation at 12050 $\mathrm{cm}^{-1}, 10 \mathrm{~mW} / \mathrm{mm}^{2}$ (red upward triangle), and subsequent irradiation at $21186 \mathrm{~cm}^{-1}, 1.2 \mathrm{~mW} / \mathrm{mm}^{2}$ (blue downward triangle), $T=65 \mathrm{~K}$.

cycle by following the evolution of the LS fraction, $\gamma_{\mathrm{LS}}$, as function of irradiation time at that temperature first for irradiation at $12050 \mathrm{~cm}^{-1}$ followed by irradiation at 21186 $\mathrm{cm}^{-1}$ (see Figure S4 in Supporting Information for spectral evolution). The observed efficiencies are in line with previous determinations of quantum efficiencies for both the lightinduced HS $\rightarrow$ LS as well as the LS $\rightarrow$ HS conversion, respectively, the latter being about 10 times more efficient. ${ }^{9}$

In conclusion, we have thus demonstrated fully reversible, persistent, and wavelength-selective optical switching of the spin state in the $2 \mathrm{D}$ iron(II) network compound $\left\{\left[\mathrm{Fe}(\mathrm{bbtr})_{3}\right]\right.$ $\left.\left(\mathrm{BF}_{4}\right)_{2}\right\}_{\infty}$, with a zero-point energy difference between the two spin states very close to zero. The persistent nature of the switching is due to strong cooperative effects, resulting in an extremely wide hysteresis with $T_{\mathrm{c}}{ }^{\downarrow}$ near or formally even below $0 \mathrm{~K}$ and $T_{\mathrm{c}}^{\uparrow}$ at $100 \mathrm{~K}$. The latter determines the maximum operating temperature of the switch. In contrast to the system discussed by Bousseksou et al., ${ }^{10}$ which operates with a combination of optical switching and temperature jump effects, the present system operates on a purely optical and wavelength selective basis. Indeed, the only way to create the system in the LS state at ambient pressure is through irradiation in the near IR. The persistent nature is also different from the metastable light-induced LS state in the dilute mixed crystal of the perchlorate system. ${ }^{16}$ In this case, the thermal relaxation is very slow but not strictly zero at temperatures even below $\sim 40 \mathrm{~K}$. It is, however, related to the partial switching observed in the compounds of some iron(II) tetrazole complexes having multiple crystallographic sites with large residual HS fractions at low temperatures, but for which cooperative effects are too small and the memory is lost already at $\sim 70 \mathrm{~K} .{ }^{11}$ The present system demonstrates the feasibility of persistent bidirectional switching in HS systems at higher temperatures and thus gives the incentive to search for systems for which $T_{\mathrm{c}}{ }^{\uparrow}$ is higher still but for which the hysteresis is still as large as the $100 \mathrm{~K}$ of the present system.

What remains to be done in order to arrive at an in depth understanding of the light-induced bistability: (i) determine the critical light-induced LS fraction for other temperatures; (ii) investigate the role of the crystallographic phase transition in a detailed X-ray crystallographic study; (iii) perform LIESST and reverse-LIESST experiments on mixed crystals in order to assess the cooperative effects quantitatively; (iv) perform experiments under external pressure in order to move $T_{c}^{\downarrow}$ and $T_{\mathrm{c}}^{\uparrow}$ to higher temperatures, the former possibly from below 0 to where the relaxation is no longer thermally quenched, and the latter to establish up to which temperature bidirectional persistent switching is feasible.

\section{ASSOCIATED CONTENT}

\section{Supporting Information}

Crystallographic data before and after irradiation at 12050 $\mathrm{cm}^{-1}$ and at a temperature of $\sim 70 \mathrm{~K}$; spectral evolution during irradiation. This material is available free of charge via the Internet at http://pubs.acs.org.

\section{AUTHOR INFORMATION}

\section{Corresponding Author}

andreas.hauser@unige.ch

\section{Notes}

The authors declare no competing financial interest.

\section{ACKNOWLEDGMENTS}

We are grateful to the Swiss Norwegian Beamlines for the provision of synchrotron beamtime and thank Dmitry Chernishov for his assistance. This work was financially supported by the Swiss National Science Foundation (Grant Number 200020-125175).

\section{REFERENCES}

(1) (a) Feringa, B; Browne, W. R, Eds.; Molecular Switches, 2nd ed.; Wiley-VCH: Weinheim, Germany, 2011; (b) Sato, O. Acc. Chem. Res. 2003, 36, 692.

(2) (a) Létard, J.-F.; Guionneau, P.; Goux-Capes, L. Top. Curr. Chem. 2004, 235, 221. (b) Bousseksou, A.; Molnár, G.; Salmon, L.; Nicolazzi, W. Chem. Soc. Rev. 2011, 40, 3313.

(3) Gütlich, P.; van Koningsbruggen, P. J.; Renz, F. Struct. Bonding (Berlin, Ger.) 2004, 107, 27.

(4) Gütlich, P.; Ksenofontov, V.; Gaspar, A. B. Coord. Chem. Rev. 2005, 249, 1811

(5) Bonhommeau, S.; Molnar, G.; Goiran, M.; Boukheddaden, K.; Bousseksou, A. Phys. Rev. B 2006, 74, 064424.

(6) Ohba, M.; Yoneda, K.; Agusti, G.; Munoz, M. C.; Gaspar, A. B.; Real, J. A.; Yamasaki, M.; Ando, H.; Nakao, Y.; Skaki, S.; Kitagawa, S. Angew. Chem., Int. Ed. 2009, 48, 4767.

(7) Hauser, A. Top. Curr. Chem. 2004, 234, 155.

(8) Létard, J. F. J. Mater. Chem. 2006, 16, 2550.

(9) Hauser, A. J. Chem. Phys. 1991, 94, 2741.

(10) (a) Cobo., S.; Ostrovski, D.; Bonhommeau, S.; Vendier, L.; Molnar, G.; Salmon, L.; Tanaka, K.; Bousseksou, A. J. Am. Chem. Soc. 2008, 130, 9019. (b) Bonhommeau, S; Molnar, G.; Cobo, S.; Ostrovski, D.; Bousseksou, A. Polyhedron 2009, 28, 1610. (c) Moussa, 
N. O.; Ostrovski, D; Martinez Garcia, V.; Molnar, G.; Tanaka, K.; Gaspar, A. B.; Real, J. A.; Bousseksou, A. Chem. Phys. Lett. 2009, 477, 156. (d) Galle, G.; Degert, J; Mauriac, C.; Etrillard, C.; Létard, J. F.; Freysz, E. Chem. Phys. Lett. 2010, 500, 18.

(11) (a) Poganiuch, P; Decurtins, S; Gütlich, P J. Am. Chem. Soc. 1990, 112, 3270. (b) Hinek, R.; Spiering, H.; Gütlich, P.; Hauser, A. Chem.-Eur. J. 1996, 2, 1435.

(12) (a) Bronisz, R. Inorg. Chem. 2005, 44, 4463. (b) Krivokapic, I.; Enachescu, C.; Bronisz, R.; Hauser, A. Inorg. Chim. Acta 2008, 361, 3616.

(13) Kusz, J; Bronisz, R.; Zubko, M; Bednarek, G. Chem.-Eur. J. 2011, 17, 6807 .

(14) Hauser, A. Chem. Phys. Lett. 1992, 192, 65.

(15) Spiering, H. Top. Cur. Chem. 2004, 235, 171.

(16) Krivokapic, I.; Chakraborty, P; Bronisz, R.; Enachescu, C.; Hauser, A. Angew. Chem., Int. Ed. 2010, 49, 8509. 